\title{
Diversification Strategies for the Service Sector
}

\author{
Subodh S. Bhat, PhD \\ Joseph L. Bonnici, PhD \\ Albert R. Caruana
}

\section{INTRODUCTION}

An analysis of the American economy shows that the service sector overshadows the manufacturing sector, both in size and in state of turmoil. The tumoil is due to the rapid expansion of franchise chains, computerization, evolving professional standards, and competilive pressures (Lovelock 1984). From the consumer's perspective, as client sensitivity intensifies and professional malpractice suits become more threatening, the issue of understanding and examining services becomes more important (Brown and Swartz 1989).

In line with Wind's (1982) observation, service decisions in a firm are not limited to individual services. A firm should take into account its service line (a number of related services), service mix (combination of service lines), and service portfolio (assortments of service mixes). The lines of demarcation among these terms are not always clear because they depend on organizational position as well as personal preferences in defining classification systems.

At the most basic level, an institution offers only a singular service

Subodh S. Bhat is Assistant Professor at San Francisco State University, San Francissco, CA 94132. Joseph L. Bonnici is Assistant Professor of Marketing, Bryant College, Smithfield, RI 02917-1284. Albert R. Caruana is affiliated with the University of Malta, Malta.

Conrespondence may be addressed to Subodh S. Bhat, Assistant Professor, San Francisco State University, 1600 Holloway Avenue, San Francisco, CA 94132.

Joumal of Professional Services Marketing, Vol. 9(1) 1993

(C) 1993 by The Haworth Press, Inc. All rights reserved. 
(Lunn 1972). Extensions of offerings within a restricted and related group of service categories constitute a service line, an example of which is the tax consulting services márket where an accountant may file a tax form on behalf of a client either by mail or through computer services linked up with the IRS office.

\section{DIVERSIFICATION}

The addition of new service lines is termed service diversification. A new service line usually involves servicing new customers and possibly using new technology, marketing strategies, and managerial skills. Pessemier (1966) describes diversification as the extension of sales into new areas to customers not currently served by the firm. Thus, diversification implies an increase in the number of service-markets in which a firm is active (Gort 1974) and is different from service-line extension, which is the widening of the line of services offered to current customers (Pessemier 1982). Hence, a distinguishing feature of diversification is the reduced dependence on one or a handful of services formerly offered (Short 1967).

The simplest case of service diversification is developing a new but related service line. It involves the expansion of offerings into service categories related to the existing categories. This strategy usually involves internal resources, or resources already available within the firm. At the other extreme, the most complex diversification occurs when expansion into unrelated service categories necessitates the use of new and external resources. In such a case, the decision to diversify is in effect an investment decision. The new service offered may have no strategic marketing fit with the existing service line; in fact, the major reason for the use of external resources is the desire to move away from dependency on existing service lines.

Between these two extremes lies diversification which involves offering unrelated services using intemal resources. Diversification is conceived in a limited manner for the purpose of this article: it relies only on existing intemal resources. Such diversification excludes strategies of acquisition and merger. Lubatkin (1987) supports the distinction between diversification and acquisition strategies, on both definitional and motivational grounds.

There is no single strategy of diversification; each firm that diversifies must choose the types of new services it will provide and the extent to which it can capitalize on existing strengths (Rumelt 1974). In this context, an important aspect to consider in any new service strategy is the 
strategic fit of the service within the overall objectives and plans of the company. The objectives for new services which are usually specified in terms of volume of business, cash flow generation, or acceptable levels of risk, have to be consistent with or complement the sales, cash flow or risk levels of existing operations. The new service must also be compatible with the overall corporate image. Diversification projects that are expected to operate within these parameters are more likely to be endorsed by management.

For this reason, the decision to diversify into a new line is rarely undertaken without taking into consideration the ramifications on existing offerings as well as future ones. There are several interdependencies which arise in the course of researching and developing, marketing, financing, and managing a new service. On the basis of these interdependencies, and restricting our discussion to marketing, we propose a set of factors which favor diversification into new service lines:

1. Availability of Unused Resources: "Slack" or unused resources in a firm may be a matter of design (McKee, Varadarajan and Pride 1989) or the result of circumstances, such as changes in demand conditions. In marketing, slack may exist in the form of unused retail space or underutilized sales personnel. New lines which capitalize on these hitherto unused resources bring cost savings to the firm. Savings flow from the absorption of costs of the previously unused resources over a larger service mix and result in a greater economic value for the firm.

2. Economies of Scale: Wind (1982) suggests that if a new offering shares the facilities currently used for other services, the expected cost interdependencies should be taken into account in the budgeting process for the new service. Although such an idea is rooted in the literature about shop-floor economies, cost interdependencies extend beyond the sharing of production facilities. In the field of marketing, such interdependencies are quite common, even for new services which at the surface level seem unrelated to existing lines. For example, in a publishing house, a new line of professional publications may share some of the transportation and warehousing routes used by a newspaper published by the same house. These cost savings arise not so much from the use of slack or unused resources as from the economies following a larger scale of operations and the distribution of overheads or fixed costs over a broader service mix. Economies of scale are a direct function of the size of operations and can arise in different areas such as advertising, transportation, and marketing research (Shepherd 1985).

At the same time, one must caution that the larger the number and the greater the variety in a firm's service portfolio, the greater are the prob- 
lems of planning, coordination, and control. At some point, instead of reaping further economies from growth, diseconomies may kick in. Munkelt (1982) observes that each successive addition to the service line may result in smaller returns to investment.

3. Synergistic Polential: Synergy results when a combination of items or elements produces an overall effect greater than the sum of the effects of individual parts. Carefully selected new service lines may result in a higher economic value for the firm than the individual current and new services considered separately. A common example in marketing is the use of a well-known name to launch a new service, which could, over time, reinforce the brand image (Munkelt 1982); the reinforced brand image brings additional value to the firm. Such is the case in the AT\&T long-distance dialing card where the recent incorporation of credit facilities under the same card reinforces the company's favorable image.

Synergy is intimately connected with the use of resources because it is the utilization of resources that can create economic value (Chatterjec 1986). In the diversification context, synergy is the greater efficiency and effectiveness in the use of resources which result from the joint running of two or more services (Lubatkin 1983).

One source of synergistic efficiencies and effectiveness generated by diversification is the achievement of intermal efficiency or " $\mathrm{x}$-efficiency," a term coined by Harvey Leibenstein (1956). Internal efficiency is attained by excellent management. It results when firms are well-managed, and employees contribute their maximum effort to use resources fully and effectively (Shepherd 1985).

A word of caution is warranted at this stage. Sometimes, instead of the desired synergistic effects, a firm may experience a net negative value. This may occur as a result of the cannibalization or the eating away of current services' sales as a result of the introduction of a new service. For example, the Post Office's overnight delivery service not only competes against UPS and Federal Express; it also competes against the other delivery services offered by the Post Office. A new service should maximize the total profit of the entire service mix (Wind 1982), and management should not focus narrowly on the new service to the extent of ignoring its overall impact on the firm. One possible approach to safeguard against overlooking possible cannibalization effects is to compute the cross-elasticity of demand between old and new services.

Extending brand names for new service lines may not always work. Yet, there have been instances of successful brand extensions in unrelated categories, such as Sears extending its name into financial services. It seems that in the case of unrelated service lines, a higher financial invest- 
ment and greater marketing effort would be needed to convince the customer that the same relative brand quality and expertise prevail (Munkelt 1982).

4. Increase in Power: Another source of diversification is the pecuniary cconomies which result from the effective use of market power. Market power refers to the extent of influence a firm exercises in the marketplace with its suppliers, customers, and other constituencies. This power usually correlates with the firm's size and number of services offered, and enables it to dictate prices both with customers and with suppliers (Lubatkin 1983).

5. Diversity of Risk: Given that a firm operates in an environment that for a large part is not controllable, diversification could result in a more effective use of future resources through a selective allocation of scarce corporate resources. For example, a music club marketing record albums to its members may elect to diversify into compact disks, with the expectation that the album industry is on its last legs. Such diversity of services offered would lessen the exposure to risk. Lubatkin (1983) observes that synergies flow from the diversification or risk-reduction economies which result when a firm lowers its risk relative to its performance; obviously, this synergistic effect is different in character from the synergy emanating from the use of resources. For this reason, Cardozo and Smith (1983) suggest that in diversifying, a firm should normatively aim for a mix of assets that are negatively intercorrelated with respect to earnings.

6. Capitalizing on "Core Strength": Bassed on his landmark study of diversification, Rumelt (1974) argues that firms which diversify into related markets perform better than firms which diversify into unrelated areas. This implies that firms with a concentration in a particular market type (for example, personal banking, or dry cleaning services) tend to perform better than firms with operations in two or more types of markets. By moving into a related area, firms are able to benefit from the synergies resulting from the use of supplementary or complementary resources. Such firms utilize this synergy by tapping the resources and talents already available in ongoing activities for use in their new service lines. In other words, they would rely heavily on "core marketing strength" (Hopkins 1987). The more the marketing know-how for a new service line is similar to that of existing service lines, the higher is the possibility of market success.

7. Operating Within "Comfort Zone": One of top management's prime responsibilities is setting the course and direction of corporate growth; they may formulate explicit policies, but more often, these policies are implicit. These policies define the acceptable borders of the new service 
effort, and the area within these borders is often called the "corporate comfort zone" (Association of National Advertisers 1985). The term "comfort zone" is broader than "core strength" since it extends the conceptual limits of excellence. The comfort zone is specified not only by the technological and firm-based capabilities but atso by the mind-set of top management For example, at the functional level, marketing management in a firm will have its own mind-set, as well as a distinct view of the firm's marketing capabilities. This results in a set of policies and guidelines, implicit and explicit, which define the "marketing comfort zone." Marketing management is more likely to support new service development within this zone's borders.

\section{CONSUMER-BASED FACTORS}

The above factors describe the use and importance of current resources in the decision to diversify. However, such an examination is incomplete to the extent that it excludes consumer-based factors which might impact the diversification plan. Brown and Swartz (1989, p. 93) observe that:

The interactive nature of ... serviccs and their often simultaneous production and consumption indicate a need to examine the perceptions of both parties involved in the service encounter (professional and client). Overall, professionals " perceptions most directly affect the design and delivery of the services offered, whereas consumer perceptions more directly determine evaluation of the services consumed. Hence, ... both parties must be considered...

Extending the marketing concept into the diversification process (Figure 1) reinforces the importance of the customer in services planning. For one thing, the marketing concept could result in more reliance on customer-oriented sources for diversification ideas (McCarthy 1978). The marketing concept philosophy suggests several aspects from the consumer's perception which could direct the diversification process.

In looking at the market from Sampson's (1970) point of view, diversification is more likely to be successful when the consumer perceives the new service as one which (1) satisfies meaningful needs and wants, (2) is outstanding in its contribution, and (3) can be readily understood. On the basis of Wasson's (1960) study, the consumer is more likely to react favorably to diversification when the new service of fers benefits in terms of (1) convenience, (2) low cost, (3) dependable performance, (4) avail- 


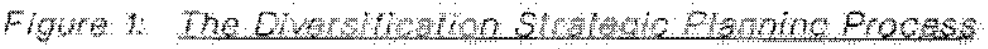

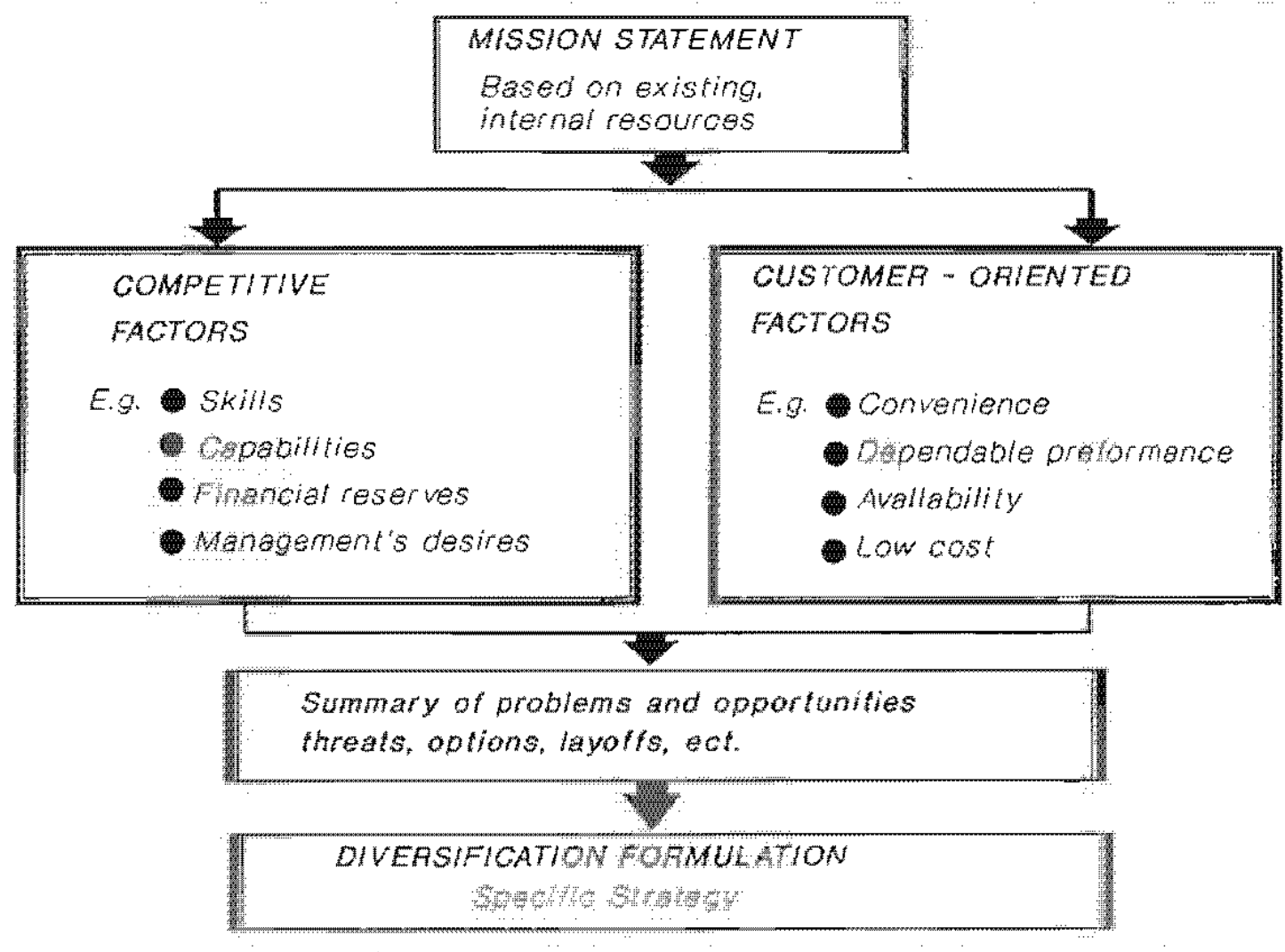


ability, both in place and in time, (5) believable advantages, and (6) conspicuous superiority.

Focusing on the customer in the strategic process is no new prescription. Because of the intangible nature of services and the customer's close contact with the service delivery process, customer orientation in strategy acquires greater relevance. The benefits of such an approach may be worth reiterating. Understanding customer needs for services, and then developing a strategy to satisfy these needs would not only result in short-term sales and profitability, but also ensure the long-run survival of the firm.

In addition, successful diversification also depends on effective implementation of strategies. The diversification program will have to be marketed to employees who, after all, are responsible for implementation. For this reason, high quality service demands a strong program of internal marketing. Intemal marketing refers to applying the marketing concept to the staff members who serve the extemal customer. This means training and serving the employees with the utmost of care and respect. These employees are the contact points with the customer. Their behavior and their friendliness are pivotal determinants of service quality, particularly because services tend to be intangible, produced at the time of consumption, and are less uniform and standardized than consumer goods (Berry 1984). Hence, diversification, much as it may stretch the company's resources, should be within the limits of internal marketing.

\section{CONCLUSION}

The concept of diversification in the service sector often presents marketers with a dilemma: How can one profitably offer consumers a diversified service portfolio while at the same time maintain high quality personalized service? To achieve this goal in the long run, service companies must design diversification strategies which capitalize on the available resources while being of value to consumers.

The concept of isolating strategic factors provides important insights into the dynamic nature of diversification strategies. In particular, it explicitly helps decision makers to evaluate their strengths and weaknesses, their exposure to risk, and their potential for further expansion. It encourages a two-pronged approach which looks both within and outside the firm and seeks to answer some of the following questions:

- Does the firm have resources that are not fully used?

- Would the new services contribute to economies of scale or synergy? 
- What is the cross-elasticity of demand among existing services and the new service?

- How powerful is the firm in the market?

- What factors are most likely to eam consumer support?

- What is the risk involved? How does it relate to the current risks of the firm?

- What is the expertise inside the firm?

Decision makers who carefully examine both the available resources as well as the consumers' probable reaction to changes in offerings are better equipped to answer the above questions and design diversification strategies which can weather turbulence in the competitive environment.

\section{REFERENCES}

Association of National Advertisers, Inc. (1985), How to Develop and Market New Products. New York: ANA.

Berry, L.L. (1984), "Services Marketing is Different," in Services Marketing: Text, Cases, and Readings, C.H. Lovelock, ed., Englewood Cliffs, NJ: Prentice-Hall, Inc., 29-36.

Brown, S.W. and T.A. Swartz (1989), "A Gap Analysis of Professional Service Quality," Journal of Marketing, 53 (April), 93.

Cardozo, R.N. and D.K. Smith (1983), "Applying Financial Portfolio Theory to Product Portfolio Decisions: An Empirical Study," Journal of Marketing, 47 (Spring), 110-9.

Chatterjee, S. (1986), "Types of Synergy and Economic Value: The Impact of Acquisitions on Merging and Rival Firms," Strategic Management Journal, 119-39.

Gort, M. (1974), "Diversification, Mergers, and Profits," in The Corporate Manager, W.M. Alberts and J.E. Segall, eds., Chicago: The University of Chicago Press.

Hopkins, D.H. (1987), "Acquisition Strategy and the Market Position of Acquiring Firms," Strategic Management Journal, 8, 535-47.

Leibenstein, H. (1966), "Allocative Efficiency vs. 'X-efficiency'," American Economic Review, 56 (June), 392-415.

Lovelock, C.H. (1984), Services Marketing: Text, Cases, \& Readings. Englewood Cliffs, NJ: Prentice-Hall, Inc.

Lubatkin, M. (1983), "Mergers and the Performance of the Acquiring Firm," Academy of Management Review, 8(2), 218-25.

(1987), "Merger Strategies and Stockholder Value," Strategic Management Journal, 8, 39-53.

Lunn, T. (1972), "Segmenting and Constructing Markets," in Consumer Market 
Research Handbook, R.M. Worcester, ed., Maidenhead, Berkshire: McGrawHill.

McCarthy, E.J. (1978), Basic Marketing: A Managerial Approach. Homewood, IL: Richard D. Irwin.

McKee, D.O., P.R. Varadarajan, and W.M. Pride (1989), "Strategic Adaptability and Firm Performance: A Market-Contingent Perspective," Journal of Marketing, 53 (July), 21-35.

Munkelt, A.G. (1982), "Optimal Breadth and Depth of the Line," in Product-Line Strategies, ed., E.L. Bailey, Conference Board Report.

Pessemier, E.A. (1966), New Product Decisions: An Analytical Approach, New York: McGraw-Hill, Inc.

(1982), Product Management: Strategy and Organization, New York: John Wiley \& Sons.

Rumelt, R.P. (1986), Strategy, Structure, and Economic Performance, Boston, MA: Harvard Business School Press.

Sampson, P. (1970), "Can Consumers Create New Products?", Journal of Market Research Society, 12 (1), 40.

Shepherd, W.G. (1985), The Economics of Industrial Organization. Englewood Cliffs, NJ: Prentice-Hall, Inc.

Short, R.A. (1967), Business Mergers. Englewood Cliffs, NJ: Prentice-Hall, Inc.

Wasson (1960), "What is 'New' about a New Product?", Journal of Marketing, (July).

Wind, Y. (1982), Product Policy: Concepts, Methods, and Strategy. Reading, MA: Addison-Wesley. 